\title{
Stress level of people with psoriasis at a public hospital ${ }^{*}$
}

\author{
Érida Silva Leovigildo ${ }^{1}$ \\ Andreia Santos Mendes ${ }^{3}$
}

\author{
Rose Ana Rios David ${ }^{2}$
}

DOI: http://dx.doi.org/10.1590/abd1806-4841.20164947

\begin{abstract}
BACKGROUND: Psoriasis is a chronic dermatosis of unknown etiology with a tendency to relapse after treatment. The disease is frequently linked to psychological stress due to the embarrassment caused by the lesions.

ОвјестіvE: To analyze the stress level presented by psoriasis patients followed at the Dermatology Service of a public hospital in Salvador, Bahia state, Brazil.

METHODS: A cross-sectional study of a consecutive convenience sample composed of 60 participants. We used Lipp's Stress Symptoms Inventory for Adults to assess stress levels. The questionnaire identifies and classifies physical and psychological symptoms according to three stages of stress: alarming, resistance, and exhaustion. We also collected socio-demographic and clinical data that could be associated with psoriasis.

RESULTS: $85 \%$ of the participants presented stress. Lipp's questionnaire results revealed that $48 \%$ were in the resistance stage and $37 \%$ in the exhaustion stage. Women presented higher levels of stress. Of the total 28 women, $64 \%$ were in exhaustion stage, $29 \%$ in the resistance stage, and only $7 \%$ presented no stress symptoms. Of the total 32 men, $44 \%$ were in resistance stage, $34 \%$ in exhaustion stage, and $22 \%$ presented no stress symptoms. Regarding physical and psychological symptoms, psychological symptomatology was prevalent (55\%).

Conclusions: Based on the number of patients in exhaustion stage, we can conclude that stress levels of the participants were high regardless the type of psoriasis and treatment duration.
\end{abstract}

Keywords: Adult health; Psoriasis; Stress, psychological

\section{INTRODUCTION}

Psoriasis, a chronic, non-contagious skin disease, affects $1 \%$ to $3 \%$ of the world population. It affects men and women in equal proportions and is more common among Caucasians..$^{1-2}$ In Brazil, there are no prevalence studies in large series, but the Brazilian Consensus on Psoriasis estimated that $1 \%$ of the population is affected by the disease. ${ }^{2}$

Despite having a still unknown cause, psychosocial factors are often related to its onset or worsening, excessively influencing the quality of life of affected people. ${ }^{3}$

Stress is one of the possible factors associated with the establishment and development of this pathology. It is considered a very strong link between mind and body and no disorder or other conditions produce such interaction. ${ }^{4}$ It also directly influences cells inflammatory and proliferative process in psoriasis. Instruments assessing stress are scarce, although this phenomenon is fully inter- connected to a better or worse quality of life and is considered an important aspect in the health-disease process. ${ }^{5}$

The clinical expression of the disease may make the individual more vulnerable to stress and provide loss in quality of life, since more than half of affected individuals suffer from peeling and constant itching. ${ }^{6}$ Due to the distress caused by lesions, reports of anger, depression, shame and anxiety feelings are common. ${ }^{7}$

There is a need for developing a transdisciplinary vision in the care of patients with psoriasis, contributing to the search for effective control and fighting against the disease. Important questions about this issue should permeate various professional disciplines related to care, making it more comprehensive, in order to minimize the complications and emotional harm. ${ }^{8}$ It is noteworthy that the loss in quality of life cannot be overlooked and should draw the attention of health professionals.

Received on 18.07.2015.

Approved by the Advisory Board and accepted for publication on 09.11.2015.

* Study conducted at Dermatology Clinic of Complexo Hospitalar Professor Edgard Santos, of the Universidade Federal da Bahia (Hupes-Ufba) - Salvador (BA), Brazil.

Financial Support: None.

Conflict of Interest: None.

Maternidade Climério de Oliveira - Salvador (BA), Brazil.

Universidade Federal da Bahia (Ufba) - Salvador (BA), Brazil.

Hospital Universitário Professor Edgard Santos (Hupes) - Salvador (BA), Brazil.

C2016 by Anais Brasileiros de Dermatologia 
Considering these aspects, this research has the general objective to analyze the stress level of people with psoriasis, accompanied in a Dermatology Service of a public hospital in Salvador (BA), and the specific purpose of identifying the stress phase in which these patients are in, as well the prevailing symptomatology, if physical or psychological, in accordance with the Lipp quadriphase model (2000). ${ }^{9}$

\section{METHODS}

This is a cross-sectional study developed in a dermatology clinic of a university hospital in the city of Salvador (BA). The institution provides medical assistance to the population and is an educational, research, graduation and post-graduation center. The specific clinic at the Dermatology Service assists about 200 people a month and has residents in dermatology, doctors and university professors. The psoriasis clinic receives the most severe cases of the disease. ${ }^{10}$

The study population consisted of users diagnosed with psoriasis, registered in the institution Dermatology Service during the period of data collection. The consecutive convenience sample consisted of 60 participants over 18 years old, who were being treated at the clinic and volunteered to participate in the study, regardless of treatment duration or severity of the condition.

Data collection was performed in the dermatology clinic once a week, in the afternoon shift, between the months of May and June 2010. The technique used for the collection was structured interview in two forms: a sociodemographic, clinical and lifestyle profile and a stress assessment. People were invited to the study before dermatologic consultation, in the waiting room of the clinic. Those who agreed to participate received all the information on the study and on the informed consent. The interview was initiated after medical consultation in a private room.

To gather data for the sociodemographic, clinical and lifestyle profile, a form was applied, composed of sociodemographic variables (gender; age; place of birth; city of residence; education; skin color, defined by self-declaration; marital status; family income), clinical (time of diagnosis and treatment; presence of psoriatic arthritis; number and place of hospitalization; age of onset of psoriasis) and lifestyle (smoker or non-smoker, and type of tobacco; alcohol use) (Chart 1).

СнARт 1: Data collection instrument related to sociodemographic and clinical variables of psoriasis and some lifestyles

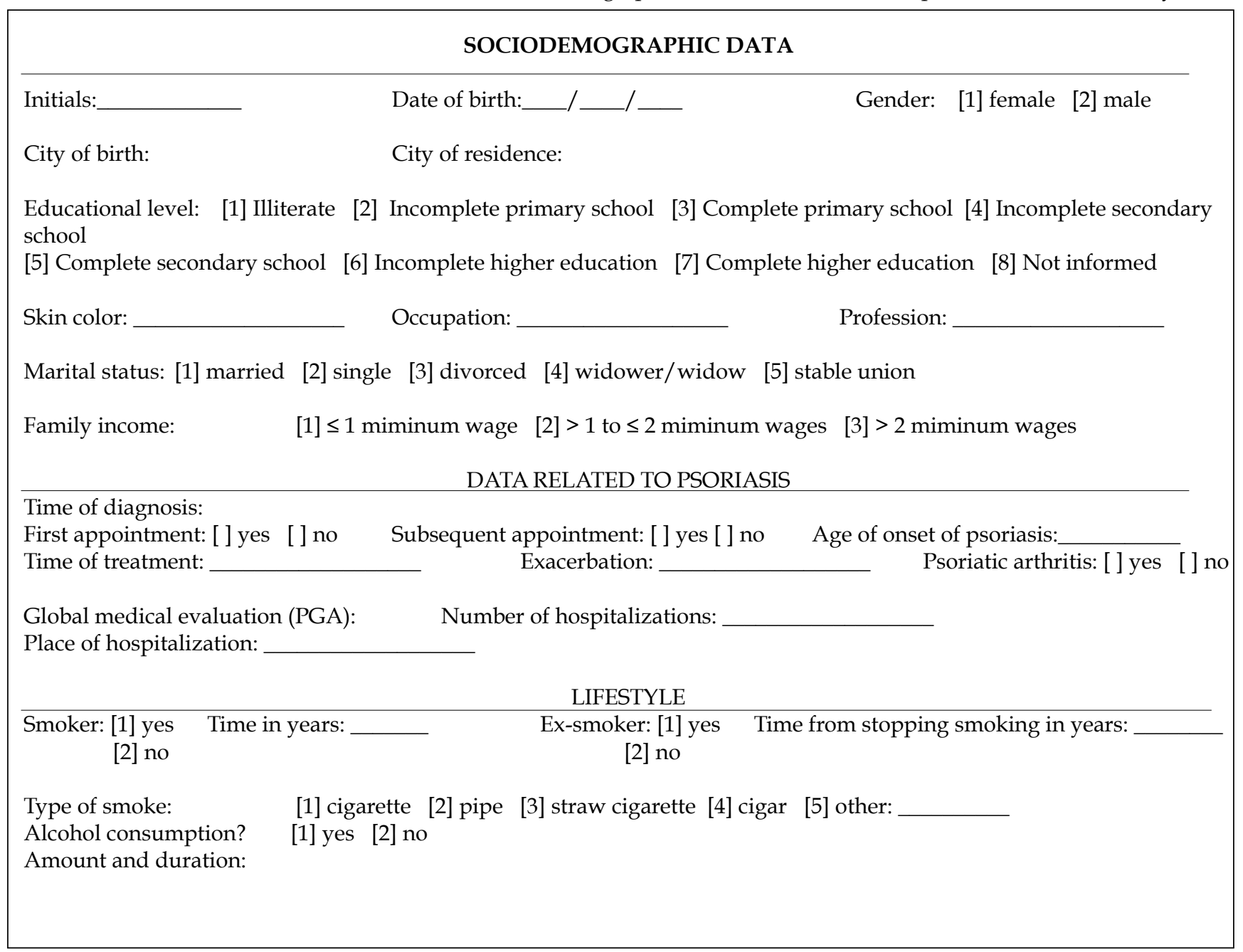


Evaluation of the stress level was conducted with the aid of Lipp's stress symptoms inventory (LSSI) for adults (Charts 2, 3, 4 and 5). ${ }^{9}$ Based on quadriphase model of stress developed by Lipp (2000), this inventory allows identifying the symptoms presented by individuals, assessing whether or not they have a diagnosis of stress, and determining the predominant symptoms (whether physical or psychological) and the phase of the stress process in which they are in (Chart 2). ${ }^{9}$ The LSSI is a structured, validated form, composed of structured questions and used in many national surveys. This instrument is self-administered; however, due to the low level of education of some study participants, application by the researcher was required. Interviews lasted a mean of 20 minutes.

LSSI is composed of three sections referring to the four phases of stress. The symptoms listed are typical of each phase. In chart 2, comprising 12 physical and three psychological symptoms, the physical or psychological symptoms that patients experienced in the last 24 hours are marked with F1 or P1. In chart 3, comprising 10 physical and five psychological symptoms, the symptoms experienced in the last week are marked with F2 or P2. In chart 4, comprising 12 physical and 11 psychological symptoms, the symptoms experienced in the last month are marked with F3 or P3. Some symptoms that appear in chart 2 reappear in chart 4 , but with a dif-

ChaRT 2: Lipp's stress symptoms inventory (LSSI) for adults. Physical and psychological symptoms of stressed participants: alarm phase

a) Mark with F1 symptoms that you have experienced in the last 24 hours.

( ) 1. Cold hands or feet

() 2. Dry mouth

() 3. Knot in the stomach

( ) 4 . Increased sweating

( ) 5 . Muscle tension

( ) 6. Jaw clenching

( ) 7. Transient diarrhea

( ) 8. Insomnia (difficulty sleeping)

( ) 9. Tachycardia (heart beating fast)

( ) 10. Hyperventilation (breathing fast)

( ) 11. Sudden and transient hypertension (high blood pressure)

( ) 12. Appetite change

Add 1 point for each F1 marked: F1 =

b) Mark with P1 symptoms that you have experienced in the last 24 hours.

( ) 13. Surge of motivation

( ) 14. Sudden enthusiasm

( ) 15. Sudden desire to start new projects

Add 1 point for each $P 1$ marked: $P 1=$
Chart 3: Lipp's stress symptoms inventory (LSSI) for adults. Physical and psychological symptoms of stressed participants: resistance and near exhaustion phases

a) Mark with F2 symptoms that you have experienced in the last week.

( ) 1. Memory problems

() 2. General discomfort without specific cause

() 3. Tingling in the extremities

( ) 4 . Constant feeling of physical wear out

( ) 5 . Appetite change

( ) 6. Onset of skin problems

( ) 7. Hypertension (high blood pressure)

( ) 8. Constant fatigue

( ) 9. Gastritis, ulcers or prolonged stomach upset

( ) 10. Dizziness or "floating" sensation

Add 1 point for each F2 marked: F2 = .......

b) Mark with P2 symptoms that you have experienced in the last week.

( ) 11. Excessive emotional sensitivity (very nervous)

( ) 12. Doubting on yourself

( ) 13. Constantly thinking of one subject

( ) 14. Excessive irritability

( ) 15. Decreased libido (unwilling to have sex)

Add 1 point for each $\mathrm{P} 2$ marked: $\mathrm{P} 2=\ldots \ldots$.

Chart 4: Lipp's stress symptoms inventory (LSSI) for adults. Physical and psychological symptoms of stressed participants: exhaustion phase

a) Mark with F3 symptoms that you have experienced in the last month.

( ) 1. Frequent diarrhea

( ) 2. Sexual difficulties

() 3. Insomnia (difficulty sleeping)

() 4 . Nausea

() 5 . Tics

( ) 6. Continued hypertension (high blood pressure)

( ) 7. Continued skin problems

() 8 . Extreme appetite change

( ) 9. Excessive gases

( ) 10. Frequent dizziness

( ) 11. Ulcer, colitis or other serious digestive problem

() 12. Heart attack

Add 1 point for each F3 marked: F3 =

b) Mark with P3 symptoms that you have experienced in the last month.

( ) 13. Inability to work

( ) 14. Frequent nightmare

() 15. Feeling incompetent in all areas

( ) 16. Desire to get away from everything

( ) 17. Apathy, depression and prolonged rage

( ) 18. Constant and excessive fatigue

( ) 19. Constantly speaking and think on only one subject

() 20. Frequent irritability without apparent cause

( ) 21. Daily distress, anxiety, fear

( ) 22. Emotional hypersensitivity

( ) 23. Loss of sense of humor

Add 1 point for each P3 marked: $\mathrm{P} 3=\ldots \ldots .$. 
ferent intensity. The reason for this gradation is that the exhaustion phase, depicted in chart 4 , generally indicates the return of some symptoms of phase 1 with a higher degree of impairment, due to resistance breakdown. The number of physical symptoms is greater than the number of psychological symptoms, and both vary from phase to phase because the stress response is thus constituted. This is why is not possible to simply use the total number of symptoms presented to conduct the diagnosis, being necessary to consult the evaluation tables. In total, LSSI includes 37 items of somatic nature and 19 items of psychological nature, and symptoms are often repeated, differing only in their intensity and seriousness. ${ }^{9}$

Results were presented in tables containing absolute numbers, percentages and simple frequencies. For the evaluation of data (Chart 5), we used the correction tables from LSSI manual. This table informs that the patient is in the alarm phase when $\mathrm{F} 1+\mathrm{P} 1>6$; in the resistance phase, when $3<\mathrm{F} 2+\mathrm{P} 2<10$; in near exhaustion phase when F2 + P2 $\geq 10$; and in exhaustion phase when F3 + P3 $>8$. It also indicates how to recognize the prevalent symptoms, whether physical or psychological.

The research project was approved by the Ethics Review Board of the institution were the study was conducted (Protocol 08.2010). Participants signed the informed consent to participate in this study, in compliance with Resolution No. 466/12 of the National Health Council.

\section{RESULTS}

Socio-demographic profile of participants

The study included 60 people with psoriasis. Results presented in table 1 show that $46.67 \%$ of interviewed subjects were women and $53.33 \%$ were men. Regarding place of birth, $40 \%$ were born in Salvador (BA) and $60 \%$ in other cities of Bahia. As for the city of residence, $58.33 \%$ lived in the capital and $41.67 \%$, in other cities of Bahia (Table 1).

Table 2 shows the results related to the age of the participants. We observed that $33.33 \%$ of the subjects were between 50 and 59 years and $25 \%$ between 40 and 49 years. The lowest percentage (5\%) corresponded to participants between 70 and 72 years old.

Table 3 depicts the results for the level of education, skin color, marital status and family income of participants. We identi-

Chart 5: Lipp's stress symptoms inventory (LSSI) for adults. LSSI evaluation form

EVALUATION
Horizontal total
A) F1 ( ) P1 ( )
B) F2 ( ) P2 ( )
C) F3 ( ) P3 ( )
Vertical total: F3 ( ) P3 ( )

Line A. F (physical) and P (psychological) symptoms of alarm phase

Line B. F (physical) and P (psychological) symptoms of resistance phase

Line C. F (physical) and P (psychological) symptoms of exhaustion phase
TABLE 1: Distribution of participants assisted in the clinic according to gender, place of birth and city of residence. Salvador (BA), 2010

\begin{tabular}{lll}
\hline Variables & \multicolumn{2}{l}{ Participants } \\
& N & $\%$ \\
\hline Gender & 28 & 46.67 \\
$\quad$ Female & 32 & 53.33 \\
$\quad$ Male & & \\
Place of birth & 24 & 40 \\
$\quad$ Capital & 36 & 60 \\
$\quad$ Interior & & \\
City of residence & 35 & 58.33 \\
$\quad$ Capital & 25 & 41.67 \\
$\quad$ Interior & $\mathbf{6 0}$ & $\mathbf{1 0 0}$ \\
Total & & \\
\hline
\end{tabular}

Source: Data collection

TABLE 2: Distribution of participants assisted in the clinic according to age group. Salvador (BA), 2010

\begin{tabular}{ccll}
\hline \multicolumn{3}{c}{ Variables } & \multicolumn{2}{c}{ Participants } \\
\multicolumn{1}{c}{ Age } & & \multicolumn{1}{c}{$\mathbf{\text { No }}$} \\
\hline 21 & 29 & 7 & 11.67 \\
30 & 39 & 8 & 13.33 \\
40 & 49 & 15 & 25 \\
50 & 59 & 20 & 33.33 \\
60 & 69 & 7 & 11.67 \\
70 & 72 & 3 & 5 \\
Total & & $\mathbf{6 0}$ & $\mathbf{1 0 0}$ \\
\hline
\end{tabular}

Source: Data collection

TABLE 3: Distribution of participants assisted in the clinic according to educational level, skin color (self-declared), marital status and family income. Salvador (BA), 2010

\begin{tabular}{|c|c|c|}
\hline \multirow[t]{2}{*}{$\overline{\text { Variable }}$} & \multicolumn{2}{|c|}{ Participants } \\
\hline & $\mathbf{N}$ & $\%$ \\
\hline \multicolumn{3}{|l|}{ Educational level } \\
\hline Illiterate & 3 & 5 \\
\hline Incomplete primary education & 13 & 21.67 \\
\hline Complete primary education & 12 & 20 \\
\hline Incomplete secondary education & 2 & 3.33 \\
\hline Complete primary education & 24 & 40 \\
\hline Incomplete higher education & 5 & 8.33 \\
\hline Complete higher education & 1 & 1.67 \\
\hline \multicolumn{3}{|l|}{ Skin color } \\
\hline Brown & 36 & 60 \\
\hline Black & 13 & 21.67 \\
\hline White & 11 & 18.33 \\
\hline \multicolumn{3}{|l|}{ Marital status } \\
\hline Married & 33 & 55 \\
\hline Single & 15 & 25 \\
\hline Divorced & 3 & 5 \\
\hline Widower/ widow & 1 & 1.67 \\
\hline Stable union & 8 & 13.33 \\
\hline \multicolumn{3}{|l|}{ Family income } \\
\hline$\leq 1$ minimum wage & 18 & 30 \\
\hline$>1$ to $\leq 2$ minimum wages & 23 & 38.33 \\
\hline$>2$ minimum wages & 19 & 31.67 \\
\hline Total & 60 & 100 \\
\hline
\end{tabular}


fied that $5 \%$ were illiterate; $21.67 \%$ had incomplete primary education and $20 \%$ had complete primary education; $3.33 \%$ had incomplete secondary education and $40 \%$ complete secondary education, corresponding to the highest percentage; $8.33 \%$ had incomplete higher education and only $1.67 \%$ had complete higher education. Regarding the self-declared skin color, $58.33 \%$ declared to be brown; $21.67 \%$ black; and $18.33 \%$ white. Concerning marital status, $55 \%$ were married; $25 \%$ single; $13.33 \%$ had stable partners; $5 \%$ were divorced; and $1.67 \%$, were widower/widow. With regard to family income, $38.33 \%$ received between one and two minimum wages; $31.67 \%$ earned more than two minimum wages; and 30\% had a family income of up to one minimum wage.

\section{Lifestyle of participants}

As shown in table 4 , only $3.33 \%$ of the participants were smokers: one for over 10 years and another for over 20 years. Among $96.66 \%$ non-smokers, $26.67 \%$ were ex-smokers and of these, $18.33 \%$ reported abstinence for over 20 years. With regard to alcohol consumption, $78.33 \%$ did not consume and $21.67 \%$ reported that only consumed socially.

\section{Clinical profile of participants}

Table 5 shows the results regarding time of diagnosis and treatment of psoriasis, number of hospitalizations due to the disease and diagnosis of psoriatic arthritis. As is was evidenced, $53.33 \%$ of the participants had confirmed diagnosis of psoriasis between three months and 10 years before the interview; $31.66 \%$ had the diagnosis between 11 and 20 years before the interview; and $11.67 \%$, between 21 and 30 years before. Regarding the treatment time at the clinic where the study was conducted, $38.33 \%$ of participants reported time of less than two years; $23.33 \%$ reported nine years or more; and $8.33 \%$ were in their first consultation.

TABLe 4: Distribution of participants assisted in the clinic according to tobacco and alcohol consumption. Salvador (BA), 2010

\begin{tabular}{lll}
\hline \multirow{2}{*}{ Variables } & \multicolumn{2}{l}{ Participants } \\
& N & $\%$ \\
\hline $\begin{array}{l}\text { Smoker } \\
\text { Yes }\end{array}$ & & 2 \\
3.33 & & \\
$\quad$ Time in years & & \\
$\quad>10$ years & 1 & 1.67 \\
$\quad>20$ years & 1 & 1.67 \\
No & & 58 \\
96.66 & & \\
Ex-smoker & & \\
Yes & 16 & 26.67 \\
$\quad$ Time from stopping & & \\
$\quad 1$ - 10 years & 5 & 8.33 \\
$\quad>20$ years & 11 & 18.33 \\
No & 44 & 73.34 \\
Alcohol comsumption & & \\
Yes & 13 & 21.67 \\
No & 47 & 78.33 \\
Total & 60 & $\mathbf{1 0 0}$ \\
\hline
\end{tabular}

Source: Data collection
Concerning psoriatic arthritis, $11.67 \%$ of interviewed subjects presented primary diagnosis, that is, joint involvement developed before skin lesions; and $6.67 \%$ reported its appearance after the primary diagnosis of plaque psoriasis or psoriasis vulgaris (Table 5).

Regarding the number of hospitalizations resulting from psoriasis, $13.33 \%$ of the participants had already been hospitalized: $8.33 \%$ had one hospitalization; $3.33 \%$ had two hospitalizations; and one patient was hospitalized three times. Moreover, $52 \%$ of participants reported that they experienced no hospitalization because of psoriasis since their diagnosis (Table 5).

In relation to the decade of onset of psoriasis, $15 \%$ reported the first decade of life; $16.67 \%$ declared the second decade; $30 \%$, the third decade, this being the highest percentage; $16.67 \%$ reported the fourth decade; and $13.33 \%$, the fifth decade. The lowest percentages correspond to the sixth and seventh decades $(6.66 \%$ and $1.67 \%$, respectively).

\section{Stress level of participants}

Based on the results, it was shown that $85 \%$ of participants had a positive diagnosis for stress: $48 \%$ were in the resistance phase and $37 \%$ were in the exhaustion phase. The alarm phase was not identified. Of the total participants, $15 \%$ presented no stress, although they reported some symptoms.

TABLE 5: Distribution of participants assisted in the clinic according to time of psoriasis diagnosis, time of treatment at the clinic, number of hospitalizations and diagnosis of psoriatic arthritis. Salvador (BA), 2010

\begin{tabular}{|c|c|c|c|}
\hline \multirow{2}{*}{\multicolumn{2}{|c|}{ Variable }} & \multicolumn{2}{|c|}{ Participants } \\
\hline & & & $\%$ \\
\hline \multicolumn{4}{|c|}{ Time of diagnosis } \\
\hline 3 months & 10 years & 32 & 53.33 \\
\hline 11 years & 20 years & 19 & 31.66 \\
\hline 21 years & 30 years & 7 & 11.67 \\
\hline 31 years & 40 years & 1 & 1.67 \\
\hline 41 years & 50 years & 1 & 1.67 \\
\hline \multicolumn{4}{|c|}{ Time of treatment at the clinic } \\
\hline 1 month & 2 years & 23 & 38.33 \\
\hline 3 years & 5 years & 10 & 16.66 \\
\hline 6 years & 8 years & 5 & 8.33 \\
\hline$>9$ years & & 14 & 23.33 \\
\hline First appo & nent & 5 & 8.33 \\
\hline Not inforr & & 3 & 5 \\
\hline \multicolumn{4}{|c|}{ Hospitalizations due to worsening of psoriasis } \\
\hline 1 hospital & ion & & 5 \\
\hline \multicolumn{4}{|c|}{8.33} \\
\hline 2 hospital & ions & 2 & 3.33 \\
\hline 3 hospital & ions & 1 & 1.67 \\
\hline No hospit & ation & 52 & 86.67 \\
\hline \multicolumn{4}{|c|}{ Psoriatic arthritis } \\
\hline Primary & & 7 & 11.67 \\
\hline Secondary & & 4 & 6.67 \\
\hline Absence & & 49 & 81.66 \\
\hline Total & & 60 & 100 \\
\hline
\end{tabular}

Source: Data collection 
Comparing men and women, the latter presented a higher level of stress. Of the 28 women, $64 \%$ were in the exhaustion phase; $29 \%$ were in the resistance phase; and only $7 \%$ presented no stress. Of the 32 men, $44 \%$ were in the resistance phase; $34 \%$ in the exhaustion phase; and $22 \%$ were not in any of the stress phases.

Of the total participants with psoriatic arthritis, $46 \%$ were in the exhaustion phase and $36 \%$ in the resistance phase.

Regarding physical and psychological symptoms, there was prevalence of psychological symptoms. In this study, the participants were affected in their entirety: the body, through physical symptoms, which prevailed in $45 \%$ of participants; and the psyche, through the psychological symptoms, prevalent in $55 \%$ of patients.

Physical and psychological symptoms of stressed participants: alarm phase

Although participants reported physical and psychological symptoms of the alarm phase, the sum of these was not enough to classify them in this phase. Physical symptoms of stress characteristic of the alarm phase and expressed by the participants in the last 24 hours prior to the interview were mainly muscle tension $(70.58 \%)$; insomnia $(52.94 \%)$; dry mouth $(49,01 \%)$; tachycardia $(45.09 \%)$; changes in appetite (39.21\%); increased sweating (37.25\%); and hyperventilation $(31.37 \%)$. At this phase, symptoms such as transient diarrhea $(5.88 \%)$ and jaw clenching/ teeth grinding $(7.84 \%)$ were less prevalent.

Concerning psychological symptoms of alarm phase, sudden enthusiasm was reported by $35.29 \%$ of stressed participants; $33.33 \%$ reported sudden urge to start new projects; and $29.41 \%$ reported sudden increase in motivation in the last 24 hours.

Physical and psychological symptoms of stressed participants: resistance and near exhaustion phases

In the resistance phase, the appearance of skin changes was a physical phenomenon manifested by $100 \%$ of respondents, once they presented skin lesions resulting from psoriasis. The other marked physical symptoms were: constant sensation of exhaustion (78.54\%); memory problems $(72.54 \%)$; constant fatigue $(70.58 \%)$; and tingling in the extremities $(52.94 \%)$. Gastritis, ulcers or very prolonged stomach upset was the set of signs and symptoms that appeared less, with a prevalence of $29.41 \%$.

The most prevalent psychological symptoms of resistance and near exhaustion phases were constant thought in one subject (78.43\%); excessive emotional sensitivity (56.86\%); excessive irritability (56.86\%); and doubt in relation to oneself $(41.17 \%)$. Decreased libido appeared with the lowest percentage $(19.60 \%)$.

Physical and psychological symptoms of stressed participants: exhaustion phase

As in resistance and near exhaustion phases, the occurrence of skin problems is also present in the exhaustion phase. Therefore, because the diagnosis of psoriasis, all participants presented it. Most significant physical signs and symptoms in this phase, occurred in the month before the interview, were: excessive gas (54.9\%); insomnia $(47.05 \%)$; extreme appetite change $(41.17 \%)$; frequent dizziness (31.37\%); nausea $(29.41 \%)$; ulcer, colitis or other serious digestive problem $(27.45 \%)$; frequent diarrhea $(25.49 \%)$; continuous hypertension (25.49\%); and sexual difficulties (23.52\%). Only one patient reported having tic disorder. There was no episode of myocardial infarction.

Regarding psychological symptoms in the exhaustion phase, present in the month before the interview, prevailed: daily anguish, anxiety and fear, reported by $74.5 \%$ of respondents, followed by emotional hypersensitivity, informed by $62.74 \%$ of patients, and feeling of incompetence in all areas, mentioned by $35.29 \%$.

All other physical and psychological symptoms of this phase were present: frequent irritability without apparent cause (54.9\%); constant thought and speech on a single subject $(49.01 \%)$; apathy, depression or prolonged anger and loss of sense of humor $(41.17 \%)$; and desire to get away from everything (39.21\%). Frequent nightmares were the symptom that appeared less $(27.45 \%)$.

\section{DISCUSSION}

Psoriasis is a common skin disease in clinical practice and it affects equally men and women. In this study, among the 60 individuals diagnosed with psoriasis, $46.67 \%$ were female and $53.33 \%$ male. ${ }^{2}$

The most significant origin of participants attended at the clinic was the interior of Bahia. This can be explained because the clinic is a reference care center for people with psoriasis, receiving the most severe cases of the disease.${ }^{10}$ In addition, the screening of patients with skin lesions that is conducted in primary care separates the ones that can be monitored and appropriately treated in primary care (such as patients with leprosy) from those whose disease has no treatment in primary care and need, therefore, to be referred for specialized care (such as patients with psoriasis). ${ }^{11}$

In the study, there was a prevalence of brown individuals with monthly income less than or equal to two minimum wages, reflecting the socio-economic situation of the majority of users of the Brazilian public healthcare system (SUS). ${ }^{12}$

Most participants reported not to consume tobacco or alcohol, which may mean that they are seeking a better quality of life, excluding from their everyday lives these factors that aggravate psoriatic lesions. According to Mota, Gon and Gon (2009), individuals with psoriasis are more vulnerable to behavioral disturbances due to difficulties in social interactions, which often produce critical and offenses related to their skin configuration. ${ }^{13}$ Individuals with skin disease, by refusing to join or consolidate social relationships, would be trying to avoid possible negative rejections or assessments. Given the previously stated, behavioral disorders, imposed by skin lesions, promote alcoholism and smoking. ${ }^{2}$ The deficit in social relations and the use of alcohol or tobacco were not compared, because it is not a behavioral analysis study.

Psoriasis can start in any decade of life, from birth to old age, but usually the first manifestations appear between 15 and 30 years of age, with no differences between genders. ${ }^{14}$ In this study, psoriasis appeared in the first decade of life in $15 \%$ of participants. Onset before the age of 15 years correlates often to family cases. ${ }^{2}$ The disease more commonly appears in late adolescence or early adulthood and may persist throughout life continuously or with interspersed episodes of remission and reactivation. Over $75 \%$ of cases 
occur before the age of 40 years and is often associated with a positive family history. These cases are unstable and affect a greater extension of the body, with a more frequent involvement of nails, high incidence of guttate type and great psychological involvement. ${ }^{15,16}$

In a small number of participants, the joint involvement was developed before the skin lesions. According to Antoni (2008), the simultaneous onset of skin and joint involvement in the disease occurs in $10 \%$ of cases, and in $15 \%$ arthritis precedes skin lesions. ${ }^{17}$ Joint involvement of psoriasis may be minimal or polyarticular, severe and deforming. Psoriasis can present with almost imperceptible lesions in the nail beds and intergluteal cleft or reach the entire body surface, as in the erythrodermic type. ${ }^{6}$

Participants in this study predominantly presented positive diagnosis for stress. The alarm phase, which is considered the stage where there is a situation of healthy reaction to stress that the individual can succeed, was not identified. It can be inferred that the fact that the study found no participant in this phase demonstrate his/her inability to return to the equilibrium state, then triggering the resistance phase, in which $48 \%$ of participants were found. The resistance phase is characterized by the body's attempt to maintain internal homeostasis. Souza et al (2005) agreed with this idea when they addressed the skin function to cover and delimit the body, protecting it from external agents and becoming fundamental in maintaining internal balance. ${ }^{18}$

If the stressing factors persist, in frequency or intensity, and the individual cannot face them in a positive way, the subject can move to the stage of exhaustion. ${ }^{9}$ It can be inferred that $37 \%$ of participants who were in exhaustion phase didn't present a positive confrontation, and the permanence of stressing factors steadily led them to an intense inner imbalance. This phase includes a period in which the individual cannot withstand the tension or restore homeostasis, although he/she has not yet fully ceded to stressing factors. It is a transition phase in which the individual will oscillate between dissatisfaction and anxiety and quiet moments. At this stage, the individual may be very vulnerable physically and psychologically, with the emergence of minor illnesses, which generally do not offer life-threatening risks, still allowing them to work and act in society. In this phase, there is worsening of physical and psychological symptoms. The body is exhausted by excessive activity and high energy consumption, and more serious illnesses may occur, such as ulcers, high blood pressure, psoriasis and vitiligo. ${ }^{19}$

Women present higher level of stress than men. This result coincides with other studies conducted in Brazil with patients with skin diseases, showing that women have a higher level of stress. Studies on skin diseases and stress consider that aesthetics, from the social point of view, is a greater pressure factor for women than for men, which should be taken into consideration when researching this subject. In general, different roles culturally set for woman, as well as hormonal changes, may also influence stress levels. ${ }^{20}$

While citing that women are often more vulnerable than men to stressing factors, recent studies indicate that gender differences in vulnerability are highly specific and depend on the type of stressing factor and disorder involved. ${ }^{21}$ Lipp (1996), in her research on stress in men and women, states that, to properly prevent and treat stress, there is a considerable interest in whether the two groups differ in the level of stress they present and how it manifests: on the cognitive or somatic area. ${ }^{22}$

Of the total participants with psoriatic arthritis, a significant percentage presented stress, which may be related to the fact that among the autoimmune rheumatic diseases, psoriatic arthritis presents recurrence and periods of exacerbation. Symptoms include persistent joint pain, pain in the insertion of tendons and ligaments (enthesitis), inflammation of the soft tissues in the distal joints, fatigue and difficulty in performing everyday activities. ${ }^{23}$

The high percentage of individuals with stress shows that although much of dermatologic patients do not present life-threatening diseases, skin diseases frequently originate a major impact on the emotional state, social relationships and daily activities of patients, due to the stigmatization caused by manifestations that are very apparent. ${ }^{4}$ According to Ludwig (2007), being affected by a skin disease, connected to the idea of dirty, ugly and contagious, probably will influence the subject's relationship with others, as well as in life in general and in the development of stress, which depends both on the individual's personality and on the organic and mental balance (health state) where he/she is in. ${ }^{5}$

There were many symptoms reported by study participants, and there was a prevalence of psychological symptoms. Many individuals reported onset or worsening of psoriasis concordant with period of stress or anxiety. ${ }^{2}$ Thus, emotional factors accompany dermatological problems and may cause physical disorders.

Although psoriasis does not affect survival, there is a negative impact on the physical and psychosocial well-being of people with this skin disease, demonstrated by the expense of quality of life. Individuals with psoriasis have a reduction in quality of life even higher than those with other chronic diseases, because they feel stigmatized, evaluated based on appearance due to the disease, which contributes to the onset of depression and even suicide attempted in more than $5 \%$ of cases. ${ }^{16}$ Psychological and emotional impact is not always related to the extent/ severity of the skin disease, although psoriasis is connected to low self-esteem and mood disorders. Therefore, it is essential that psychosocial aspects are always taken into consideration when evaluating therapeutic options. ${ }^{2}$

The alarm phase was not identified in this study, although some symptoms of this phase have been reported. It was observed that the feeling of constant exhaustion was the physical symptom that prevailed. This symptom is one of the characteristics of fatigue syndrome, defined as a physical or mental energy burnout. ${ }^{24}$ Regarding memory problems, the second most frequent symptom in the classification, there is a correlation with cortisol levels, increased in this phase, which influence the structure and hippocampus function, producing changes in cognition and memory. ${ }^{25}$

In the resistance phase, the prevalent psychological symptoms were: constant thought in one subject $(78.43 \%)$; excessive emotional sensitivity (56.86\%); excessive irritability (56.86\%); and doubts about oneself. These aspects may be related to the fact that psoriasis is a chronic disease in which the stress and anxiety are mentioned by many patients as triggering or worsening factors. ${ }^{2}$

These psychological symptoms are also linked to feelings of rejection and stigmatization that may be present in the daily lives of people with psoriasis and compromise their social adaptation. 
The sense of discrimination about the physical appearance accompanies individuals with this disease, causing great dissatisfaction with themselves. ${ }^{26}$

Of the 51 subjects characterized as stressed, $41.17 \%$ reported that they doubted themselves. Situations of discrimination and rejection, plus the very constitution of personality based on a poor body image due to the disease, can also influence self-acceptance capacity and the individual's personal satisfaction. ${ }^{4}$

An increasing amount of sociological and psychological data indicates that the cosmetic disfigurement may have serious consequences for the individual's life, creating social embarrassment, anxiety and shame. ${ }^{27}$ This may explain the psychological symptoms reported in the exhaustion phase, such as a daily feeling of distress, anxiety and fear (74.5\% of the participants); apathy, depression or prolonged anger; loss of sense of humor; and desire to get away from everything.

Emotional hypersensitivity (reported by $62.74 \%$ of individuals), constant and excessive fatigue and the inability to work (occurred in $56.86 \%$ and $43.13 \%$ of respondents, respectively) occurs because psoriasis also affects motivation, self-esteem and mood of patients, impacting on their social and educational development, as well as work performance. It can also be responsible for depression, including suicidal ideation. ${ }^{2}$ The aforementioned aspects also explain the fact that $35.29 \%$ of participants have informed sense of incompetence in all areas.

The many symptoms reported by participants demand that these are viewed holistically, taking into consideration not only the skin lesions and the physical signs seen by clinical eyes of health professionals, but also the symptoms of the soul, understood in the investigation of individual subjectivity.

The stress influences disease progression and therapy. Over $60 \%$ of people with psoriasis describe stress as a triggering or exacerbating factor of the disease. Therefore, the psychological intervention plays an important role in the management of this disease, especially in parallel to pharmacological treatment, producing a significant improvement in disease severity. ${ }^{16}$

There are numerous dermatoses that, being chronic and requiring continuous treatment, burden the public healthcare system, requiring a more comprehensive and interdisciplinary care for better treatment. The global vision of a human being requires adapting different approaches to produce a more complete understanding of its internal and external dynamics, which needs not isolated and fragmented interventions, but different actions aiming at the same goal: the search for a state of full health within individual and collective possibilities. ${ }^{28}$

\section{CONCLUSIONS}

The stress level of people with psoriasis study who participated in this study was high, regardless of the type of psoriasis and the treatment time, since many participants were in the exhaustion phase. In the several studies analyzed, using LSSI and comprising diverse subjects (doctors, nurses, judges, men, women, people with various skin diseases), this phase of stress was not detected, and the resistance and near exhaustion phases were the most cited. Given these results, we can infer what many other studies on skin diseas- es have reported: that psoriasis is a condition that induces stress worsening.

Through LSSI, it was identified a significant percentage of subjects in this study who were in the resistance phase, demonstrating that there is an attempt to maintain homeostasis. The persistence of stressing factors leads the individual to a more serious stage of stress. It becomes necessary then a professional intervention to prevent more serious situations of stress, helping the patient to identify its positive potential for the reintegration of health.

It is unquestionable that psoriasis has an impact on quality of life of affected people. Stress, as an important factor in this respect, needs to be evaluated and understood by the patient and the professional who assists him/her, as the process of coping with the disease is a stressor focus. Understanding this phenomenon, its phases and effects, both physical and mental, provides professionals a more comprehensive knowledge, allowing them to clarify doubts from people about how this variable can influence the health condition as a whole.

This study did not assessed stress as a triggering or aggravating factor of the disease, although many participants have reported, during the interview, that psoriasis was triggered after stressful events, such as job loss, death of a spouse, cancer diagnosis, among others. Some patients have reported worsening of the condition in times of worry and anguish.

The fact that subjects who had other health problems, in addition to psoriasis, were not evaluated separately, is a limitation of the study, since interference in LSSI results may have occurred due to the absorption of losses relating to other pathology.

The predominance of psychological symptoms shows that it is essential to consider significant the relationship between skin disease, emotions and conflicts. It was observed that these people need an interdisciplinary approach that encompasses and integrates emotional and physical aspects and assist them in their entirety, in an approach that comprises other aspects in addition to the skin surface. Therefore, the combination of the medical and psychological follow-ups would be of great value to the study participants.

Although numerous studies emphasize the inseparability of emotional and physical aspects (psyche and skin) and their influence on the health-disease process, viewing the individual as a biopsychosocial being and defending the holistic perception of health, in practice this integration is still neglected.

Knowing the characteristics of psoriasis, as well as therapeutic methods, the factors that influence its onset, its worsening and its recurrence, and assess factors that affect the quality of life of affected people, especially in the psycho-emotional sphere (such as stress), allows health professionals involved in caring for people with psoriasis to strengthen and (re)build their care practice, expanding the scientific knowledge for the adoption of effective interventions when assisting patients in this condition.

Such studies may support actions to better know the individual based on his/her beliefs, values, feelings, concepts, behavior, personality and spirituality, which characterizes him/her as a unique being. All these aspects need to be considered in the healthdisease-care process.] 


\section{REFERENCES}

1. Langham S, Langham J, Goertz HP, Ratcliffe M. Large-scale,prospective, observational studies in patients with psoriasis and psoriatic arthritis: a systematic and critical view. BMC Med Res Methodol. 2011;11:32.

2. Consenso Brasileiro de Psoríase 2012. Guias de avaliação e tratamento. In: Psoríase: consenso e algoritmo de tratamento. Rio de Janeiro: Sociedade Brasileira de Dermatologia; 2009. p.11-20.

3. Arruda CS, Nogueira E, Oliveira MS, Pereira ER, Silva RMCRA. Avanços e desafios da enfermagem na produção científica sobre psoríase. Rev Bras Enferm. 2011;64:168-75.

4. Silva KS, Silva EAT. Psoríase e sua relação com aspectos psicológicos, stress e eventos da vida. Estud psicol. 2007;24:257-66

5. Ludwig MWB. 0 Adoecimento da pele: um estudo de qualidade de vida, estresse e localização da lesão dermatológica [dissertação]. Porto Alegre (RS): Pontifícia Universidade Católica do Rio Grande do Sul; 2007. 93 p.

6. Ruiz DG, Azevedo MNL, Santos OLR. Artrite psoriásica: entidade clínica distinta da psoríase? Rev Bras Reumatol. 2012;52:630-38.

7. Lee YW, Park EJ, Kwon IH, Kim KH, Kim KJ. Impact of Psoriasis on Quality of Life: Relationship between Clinical Response to Therapy and Change in Health-related Quality of Life. Ann Dermatol. 2010;22:389-96.

8. Arruda CS, Nogueira E, Oliveira MS, Pereira ER, Silva RMCA. Avanços e desafios da enfermagem na produção científica sobre psoríase: revisão. Rev Bras Enferm. 2010;63:264-73.

9. Lipp MEN. Manual do inventário de sintomas de stress para adultos de Lipp. São Paulo: Casa do Psicólogo; 2000.

10. Saúde.gov.br [internet]. Secretaria da Saúde do Estado da Bahia. Assessoria de comunicação social. Complexo HUPES participa de campanha no dia nacional da psoríase. [acesso 25 mar 2015]. Disponível em: http://www.inovarh.ufba.br/ noticias $/ 250$

11. Santos Júnior A, Andrade MGG, Zeferino AB, Monte Alegre S, Moraes AM, Velho PENF. Prevalência de dermatoses na rede básica de saúde de Campinas, São Paulo - Brasil. An Bras Dermatol. 2007;82:419-24

12. Santos MALS, Lima CS, Góes HFO, Paixão JGM, Rodrigues Neto TS. Clinical and epidemiological profile of psoriasis patients. Rev Para Med. 2013;27:35-40.

13. Mota CMS, Gon MCC, Gon AS. Análise Comportamental de Problemas de Interação Social de Indivíduos com Psoríase. Interação Psicol. 2009;13:155-64.

14. Chouela EN. Epidemiología y genética de la psoriasis. Dermatol Argent. 2011;17:236-9.

15. Rodrigues AP, Teixiera RM. Desvendando a psoríase. RBAC. 2009;41:303 -9.

16. Langley RG, Krueger GG, Griffiths CE. Psoriasis: epidemilogy, clinical feature, and quality of life. Ann Rheum Dis. 2005;64:ii18-23.

17. Antoni CE. Psoriatic arthritis: etiology and pathogenesis. In: Hochber MC, Silman AJ, Smolen JS, Weinblatt ME, Weisman MH. Rheumatology. 4. ed. Philadelphia: Elsevier; 2008.

18. Souza APFS, Carvalho FT, Rocha KB, Lages MN, Calvetti PU, Castoldi L. Associação de eventos estressores ao surgimento ou agravamento de vitiligo e psoríase. Psico. 2005;36:167-74.

19. Lipp MEN. 0 estresse no Brasil: pesquisas avançadas. Campinas: Papirus; 2004

20. Lipp MEN. Mecanismos Neuropsicofisiológicos do Estresse: teoria e aplicações clínicas. São Paulo: Casa do Psicólogo; 2003. p. 89-98.

21. Calais SL, Andrade LMB, Lipp MEN. Diferenças de Sexo e Escolaridade na Manifestação de Stress em Adultos Jovens. Psicol Reflex Crit. 2003;16:257-63.

22. Lipp MEN (Org). Pesquisas sobre 0 estresse no Brasil: saúde, ocupações e grupos de Risco. São Paulo: Papirus Editora; 1996. p.17-31.

23. Cantini F, Niccoli L, Nannini C, Kaloudi O, Bertoni M, Cassarà E. Psoriatic arthritis: a sistematic Review. Int J Rheum Dis. 2010;13:300-17.

24. França ACL, Rodrigues AL. Estresse e trabalho: uma abordagem psicossomática. São Paulo: Atlas; 2002. p. 27-30.

25. Vanitallie T. Stress: a risk factor for serious illness. Metabolism. 2002:51:40-5

26. Silva JDT, Müller MC. Uma integração teórica entre psicossomática, stress e doenças crônicas de pele. Estud Psicol. 2007;24:247-56.

27. Nogueira L, Zancanaro P, Azambuja R. Vitiligo e emoções. An Bras Dermatol. 2009; 84:41-5.

28. Mota LS, Costa VHF, Xavier RCNG, Vieira VB, Valois AJO, Lins RMP et al. Estresse, neuropsicoimunomodulação e dermatoses: 0 sofrimento psíquico expresso na pele. Neurobiologia. 2009;72:111-8.
MAILING ADDRESS:

Érida Silva Leovigildo

Rua Optaciano da Silva Oliveira, $n^{\circ} 139$, bl. 9, ap. 1

Brotas

40276-070 Salvador, BA

Email:eridasl@hotmail.com

How to cite this article: Leovigildo ES, David RAR, Mendes AS. Stress level of people with psoriasis at a public hospital. An Bras Dermatol. 2016;91(4):446-54. 